\begin{tabular}{|c|c|}
\hline Title & Control method for a combined active filter system employing a current source converter and a high pass filter \\
\hline Author(s) & Fukuda, S.; Endoh, T. \\
\hline Citation & $\begin{array}{l}\text { IEEE T ransactions on Industry A pplications, 31(3), 590-597 } \\
\text { https://doi.org/10.1109/28.382120 }\end{array}$ \\
\hline Issue Date & $1995-05$ \\
\hline Doc URL & http:/hdl .handle.net/2115/5966 \\
\hline Rights & $\begin{array}{l}\text { C1995 IEEE. Personal use of this material is permitted. However, permission to reprint/republish this material for } \\
\text { advertising or promotional purposes or for creating new collective works for resale or redistribution to servers or lists, } \\
\text { or to reuse any copyrighted component of this work in other works must be obtained from the IEEE. } \\
\text { IEEE, IEEE Transactions on Industry A pplications , 31(3), 1995, p590-597 }\end{array}$ \\
\hline Type & article \\
\hline File Information & ITIA31_3.pdf \\
\hline
\end{tabular}

Instructions for use 


\title{
Control Method for a Combined Active Filter System Employing a Current Source Converter and a High Pass Filter.
}

\author{
Shoji Fukuda, Member, IEEE, and Takayoshi Endoh
}

\begin{abstract}
This paper describes a control method with a combined filter system which senses load current, source current, and line voltage to create reference signals for an active filter. The transfer function of the active filter is identified and is used for the control system design. It is shown that the source current feedback is most effective to suppress the harmonicenlarging effects due to parallel resonance and the harmonic current generated by source harmonic voltages. A small setup controlled by a DSP was built, and the validity of the proposed method was demonstrated by experimental results.
\end{abstract}

\section{INTRODUCTION}

$\mathbf{R}$ ECENTLY, static power converters have been widely used in many industries. With this trend wide-band current harmonics and reactive power generated by the converters are becoming a troublesome problem in ac power lines. Thus, research interest in the development of active power filters (AF) to solve the problem is growing.

Basically there are two kinds of AF's, the current source active filter (CSAF) and the voltage source active filter (VSAF). Major research efforts have been focused on VSAF because of its lower running loss compared to CSAF. CSAF is, however, superior in controllability and reliability. Furthermore, if superconducting coils could be practically used, CSAF would be promising, because it can operate in a lossless manner; absorbing not only harmonics and reactive power but active power variations. We have already proposed a combined filter system [1], [2] using a current source active filter and a high pass filter (HPF) to obtain wide-band compensation performance. With this system, however, some problems have remained unsolved:

1) parallel resonance between the source impedance and $\mathrm{HPF}$,

2) inflow of harmonic currents to HPF which are produced by source harmonic voltage, and

3) drawbacks stem from analog control such as sensitivity to noise and temperature.

Paper IPCSD 94-85, approved by the Industrial Power Converter Committee of the IEEE Industry Applications Society for presentation at the 1993 Power Conversion Conference-Yokohama 1993, Yokohama, Japan, April 19-21 and the 5th EPE Conference, Brighton, UK, September 13-16, 1993. Manuscript released for publication October 27, 1994.

S. Fukuda is with the Department of Electrical Engineering, Hokkaido University, Sapporo, 060 Japan.

T. Endoh was with the Department of Electrical Engineering, Hokkaido University, Sapporo, 060 Japan. He is now with the Research Division, Komatsu Ltd., Hiratuka, 254, Japan.

IEEE Log Number 9409290.

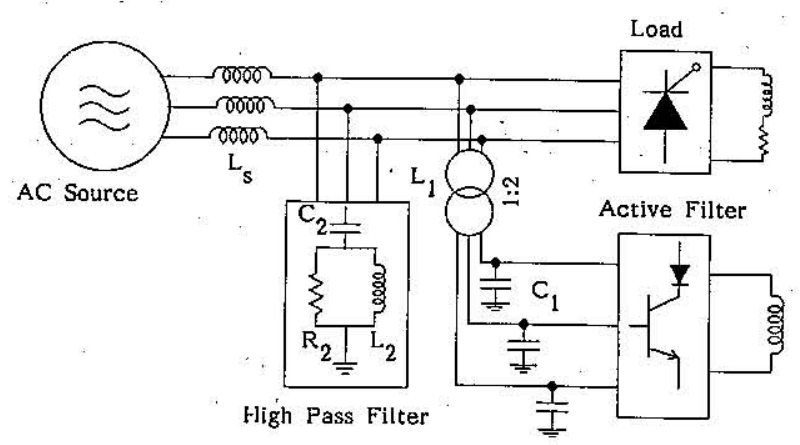

Fig: 1. Configuration of active filter system.

It is known that source current feedback [3], [4] is useful for suppressing problems 1) and 2). If such feedback is adopted, stable control system design is required as feedback may introduce instability into the system. A control system design for VSAF has been reported in [4], but it is not valid for CSAF because the method used for creating compensation current is totally different from that of VSAF.

One target of this paper is to establish a method of control system design for CSAF. In the CSAF system under consideration, source current and line voltage feedbacks are added to load current feedforward to suppress problems 1) and 2). It is found that the transfer characteristics of CSAF are approximately represented by a first-order lag system. Then stability investigations are carried out based on a transfer function approach, and a stable feedback system design is proposed.

The other target is to adopt digital control using a digital signal processor (DSP) [2]. In this situation, however, there exists a time-lag in the output due to the computation by DSP, which causes serious deterioration in the filter performance. It is shown that the source current feedback is also very effective to suppress the influence of the time-lag.

Finally it is demonstrated by experimental and simulation results that a properly designed CSAF with load current feedforward, and source current and line voltage feedbacks, exhibits excellent compensation performance solving problems of 1) to 3) and that of the time-lag.

\section{Circuit CONFIGURATION}

Fig. 1 shows the combined filter system using a current source converter (CSC) and a high pass filter. The AF is connected to ac power lines through a transformer with a turn 


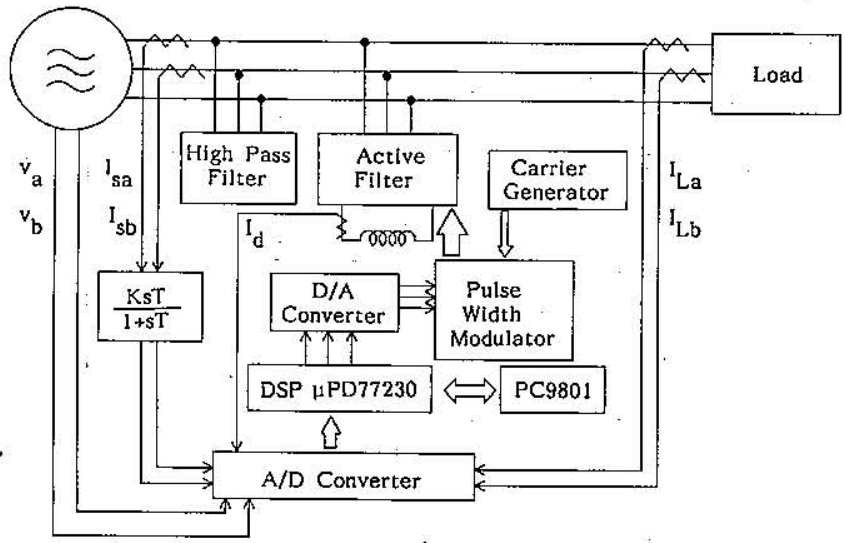

Fig. 2. Configuration of active filter control system.

ratio of $2: 1$. Fig. 2 shows the control circuit configuration. The DSP is used to calculate the current reference of the AF. The PWM control is a comparison-based method with triangular carrier waves [1], and the sampling and carrier frequencies are the same, $10 \mathrm{kHz}$. The functions of the $\mathrm{AF}$ are

1) compensation of low order harmonics in the load current,

2) suppression of parallel resonance between the source side impedance and the HPF, and

3) suppression of harmonic current generated by the source side harmonic voltage.

The functions of the HPF are

1) compensation of high order harmonics in the load current, and

2) elimination of carrier frequency components generated by the AF.

The constants are as follows: source side impedance $L_{\dot{s}}=$ $1.0 \mathrm{mH}, R_{s}=0.6 \Omega, C_{1}=2.0 \mu \mathrm{F}$, leakage inductance of the transformer $L_{1}=4.0 \mathrm{mH}$, high pass filter $C_{2}=100$ $\mu \mathrm{F}, L_{2}=0.6 \mathrm{mH}$, and $R_{2}=2.0 \Omega$. The HPF design was described in [5].

\section{CONTROL METHOD OF THE ACTIVE FILTER}

A per-phase equivalent circuit of the AF and the load system for harmonics are shown in Fig. 3, where $I_{\mathrm{Lh}}$ and $I_{\text {sh }}$ denote the load and source harmonic currents, respectively, and $V_{\mathrm{sh}}$ denotes the source harmonic voltage. The transfer function $G_{z 1}$ from the AF current $I_{\mathrm{AF}}$ to $I_{\mathrm{sh}}$ is given by

$$
G_{z 1}=\frac{I_{\mathrm{sh}}}{I_{\mathrm{AF}}}=\frac{\frac{Z_{H}}{j \omega C_{1}}}{\left(Z_{H}+Z_{s}\right) Z_{1}+Z_{s} Z_{H}}
$$

where $\omega$ is the fundamental angular frequency of the source. $Z_{s}, Z_{H}$, and $Z_{1}$ denote the source impedance, the resultant HPF impedance, and the series impedance of $C_{1}$ and $L_{1}$, respectively. The Bode plot of $G_{z 1}$ is shown in Fig. 4 where it has two crests due to the parallel resonance between $L_{2}+L_{s}$ and $C_{2}$ at $400 \mathrm{~Hz}$, and between $L_{1}$ and $C_{1}^{\prime}$ (referred to the line side) at $3560 \mathrm{~Hz}$. In particular, the former resonance is a problem, as it enlarges harmonics around $400 \mathrm{~Hz}$. The transfer function from $I_{\mathrm{Lh}}$ to $I_{\mathrm{sh}}$ is defined as $G_{z 2}=I_{\mathrm{sh}} / I_{\mathrm{Lh}}$. $G_{z 2}=G_{z 1}$ in the low-frequency range ( $\left.<1500 \mathrm{~Hz}\right)$.

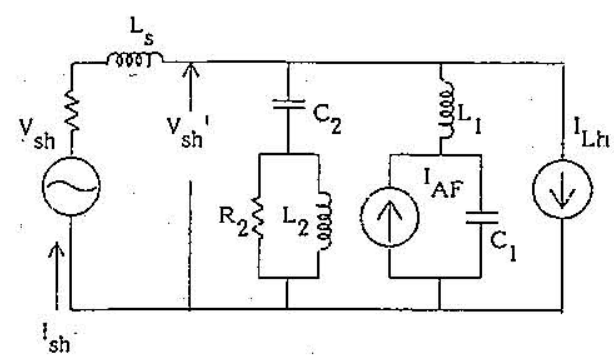

Fig. 3. Equivalent circuit for harmonics per phase.

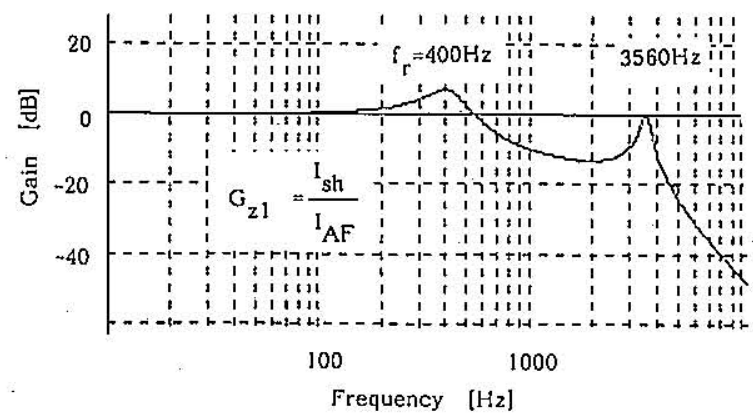

Fig. 4. Gain characteristic of $G_{z 1}$.

\section{A. Harmonic Current Sensing}

The instantaneous real and imaginary power theory [6] is used for harmonic calculation. There are three current sensing methods, as shown in Fig. 5.

Load current sensing is shown in Fig. 5(a), in which the AF output current is controlled in the feedforward way

$$
I_{\mathrm{AF}}=I_{\mathrm{Lh}} \text {. }
$$

Thus the source current will be given by

$$
I_{\mathrm{sh}}=\left(G_{z 2}-G_{\mathrm{AF}} G_{z 1}\right) I_{\mathrm{Lh}}+\frac{V_{\mathrm{sh}}}{Z_{H 1}+Z_{s}}
$$

where $G_{\mathrm{AF}}$ is the transfer function of $\mathrm{AF}$, and $Z_{H 1}$ is the parallel combination of the impedances $Z_{H}$ and $Z_{1}$. Since $G_{z 2}=G_{z 1}$ in the low-frequency region, the harmonic current originating from the load current would be zero in the same region if $G_{\mathrm{AF}}=1$. In practice, however, as $G_{\mathrm{AF}}=1$, some harmonics remain uncompensated for. In particular, the resonant frequency components in the remainder are enlarged in the source current by the parallel resonance, which causes a problem. The harmonic current generated by $V_{\mathrm{sh}}$ will not be compensated for at all, which causes another problem. However reactive power compensation is easy.

Source current sensing is shown in Fig. $5(\mathrm{~b})$, in which $I_{\mathrm{AF}}$ is controlled by the $I_{\mathrm{sh}}$ feedforward through the transfer function $G_{i}$ in the following manner assuming $G_{\mathrm{AF}}=1$ :

$$
I_{\mathrm{AF}}=G_{i} I_{\mathrm{sh}} \text {. }
$$

Thus we have

$$
I_{\mathrm{sh}}=\frac{G_{z 2} I_{\mathrm{Lh}}+\frac{\dot{V}_{\mathrm{sh}}}{Z_{H 1}+Z_{s}}}{1+G_{i} G_{\mathrm{AF}} G_{z 1}} .
$$




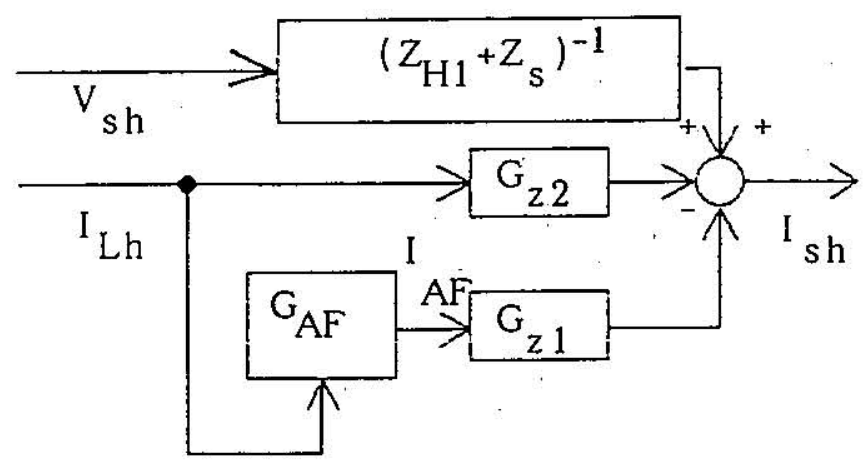

(a)

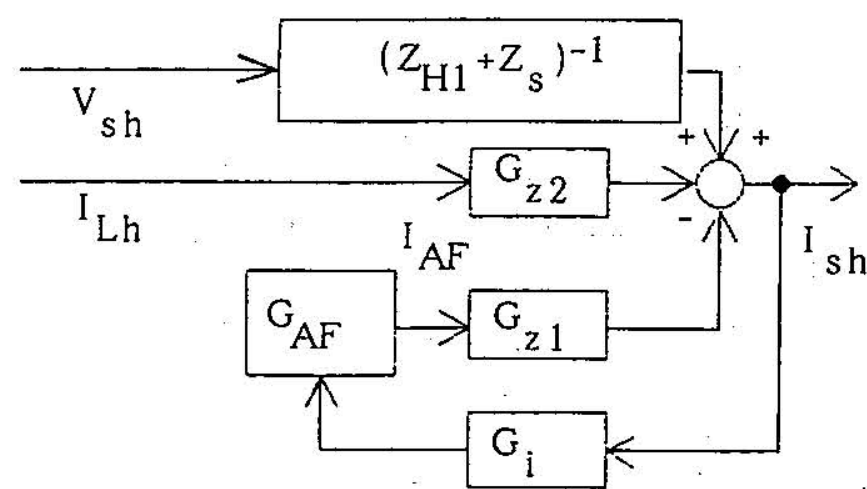

(b)

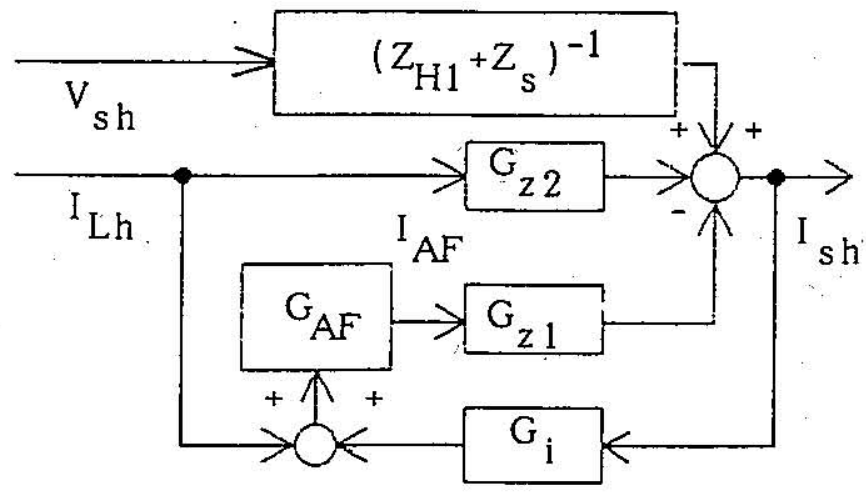

(c)

Fig. 5. Block diagram of three harmonic currents sensing methods. (a) Load current sensing. (b) Source current sensing. (c) Load and source currents sensing.

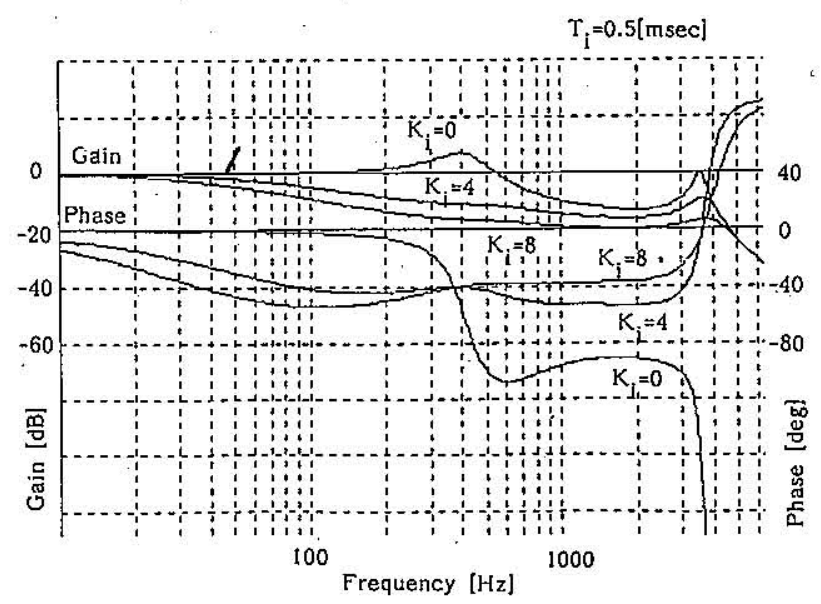

Fig. 6. Bode plots of $I_{\mathrm{sh}} / I_{\mathrm{Lh}}$.

A phase-lead element is used for $G_{i}$ to compensate for the phase-lag property of $G_{z 1}$ as

$$
G_{i}=\frac{K_{i} T_{i} s}{1+T_{i} s} .
$$

From (5) it is seen that harmonics generated by $V_{\text {sh }}$ as well as $I_{\mathrm{Lh}}$ can be suppressed if the gain, $K_{i}$, is higher than unity. The gain, $I_{\mathrm{sh}} / I_{\mathrm{Lh}}$, is illustrated in Fig. 6 under $G_{\mathrm{AF}}=1$ and $V_{\text {sh }}=0$. In the figure, the crests disappear as $K_{i}$ becomes high, which means that the parallel resonance is suppressed. However, as $I_{\mathrm{Lh}}$ is not sensed, reactive power compensation is difficuit.
Load and source current sensing is shown in Fig. 5(c). In this case $I_{\mathrm{AF}}$ is controlled by the $I_{\mathrm{Lh}}$ feedforward and $I_{\mathrm{sh}}$ feedback in the following manner:

$$
I_{\mathrm{AF}}=I_{\mathrm{Lh}}+G_{i} I_{\mathrm{sh}}
$$

Therefore we have

$$
I_{\mathrm{sh}}=\frac{\left(G_{z 2}-G_{\mathrm{AF}} G_{z 1}\right) I_{\mathrm{Lh}}+\frac{V_{\mathrm{sh}}}{Z_{H 1}+Z_{s}}}{1+G_{i} G_{\mathrm{AF}} G_{z 1}}
$$

This sensing method exhibits the best filtering performance because it has advantages of both $I_{\mathrm{Lh}}$ feedforward and $I_{\mathrm{sh}}$ feedback, that is, compensation for load harmonics and reactive power is possible by the $I_{\mathrm{Lh}}$ sensing, and suppression of the effects of parallel resonance and $V_{\text {sh }}$ is also possible by $I_{\text {sh }}$ sensing.

\section{B. Line Voltage Harmonics Sensing}

Here the line voltage feedback is added to $I_{\mathrm{Lh}}$ feedforward and $I_{\text {sh }}$ feedback. The sensed harmonic voltage $V_{\mathrm{sh}}^{\prime}$ will be

$$
V_{\mathrm{sh}}^{\prime}=V_{\mathrm{sh}}-Z_{s} I_{\mathrm{sh}} \text {. }
$$

This voltage is used for creating the compensation current reference by

$$
I_{\mathrm{AF}}=I_{\mathrm{Lh}}+G_{i} I_{\mathrm{sh}}+G_{v} V_{\mathrm{sh}}^{\prime} \text {. }
$$

The control block diagram is shown in Fig. 7. Thus we have

$$
I_{\mathrm{sh}}=\frac{\left(G_{z 2}-G_{\mathrm{AF}} G_{z 1}\right) I_{\mathrm{Lh}}+\left(\frac{1}{Z_{H 1}+Z_{s}}-G_{v} G_{\mathrm{AF}} G_{z 1}\right) V_{\mathrm{sh}}}{1+\left(G_{i}-G_{v} Z_{s}\right) G_{\mathrm{AF}} G_{z 1}}
$$




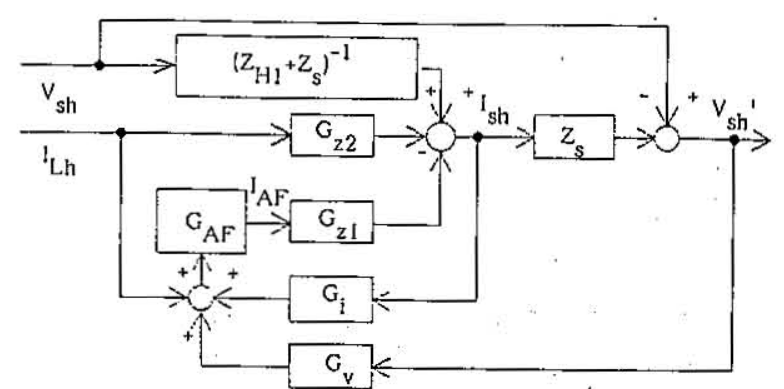

Fig. 7. Block diagram of harmonic current and voltage sensing method.

TABLE I

Residual Current AFter Compensation

\begin{tabular}{rll}
\hline $\begin{array}{c}\text { Order } \\
k\end{array}$ & $\begin{array}{r}\text { Residual } \\
\Delta T=0.1 \mathrm{~ms}\end{array}$ & $\begin{array}{c}\text { Current } J_{s k} \\
\Delta T=0.2 \mathrm{~ms}\end{array}$ \\
\hline 5 & $15.7 \%$ & $31.3 \%$ \\
7 & 21.9 & 43.6 \\
11 & 34.4 & 67.7 \\
13 & 40.6 & 79.4 \\
\hline
\end{tabular}

where $V_{\mathrm{sh}}^{\prime}$ is used through the transfer element $G_{v}$. From simulation-based stability investigations it has been found that $G_{v}$ should be a proportional gain as

$$
G_{v}=K_{v} .
$$

The voltage-sensing method is not useful if it is used alone, but if used together with $I_{\mathrm{Lh}}$ and $I_{\mathrm{sh}}$ sensing the compensation characteristics can be improved further.

\section{Residual Harmonic Currents}

Here the influence of a time-lag in the AF output due to the computation time needed by DSP is examined [5]. Consider the compensation of the $k$-th order harmonic current with the unity amplitude, $i_{L k}=\sin k \omega t$, under an ideal AF gain characteristic, $\left|G_{\mathrm{AF}}\right|=1$, with $I_{\mathrm{Lh}}$ sensing. If the time-lag is $\Delta T$, the residual harmonic current after compensation, $j_{s k}$, will be expressed by

$$
J_{s k}=\sin k \omega t-\sin k \omega(t-\Delta T)=J_{s k} \cos k \omega(t-\Delta T)
$$

where

$$
J_{s k}=2 \sin (k \omega \Delta T / 2) .
$$

$J_{s k}$ values for $10-\mathrm{kHz}$ and $5-\mathrm{kHz}$ samplings are shown in Table I. It is seen that compensation performance gets worse as the harmonic order becomes higher or the sampling frequency becomes lower. In particular, with our AF, the residual harmonics between the 5th and 11th orders are serious because they are close to the resonant frequency $400 \mathrm{~Hz}$. As AF characteristics are practically not ideal, the situation becomes more serious. Equation (8), however, indicates that the source current feedback is effective to suppress the residual harmonics.

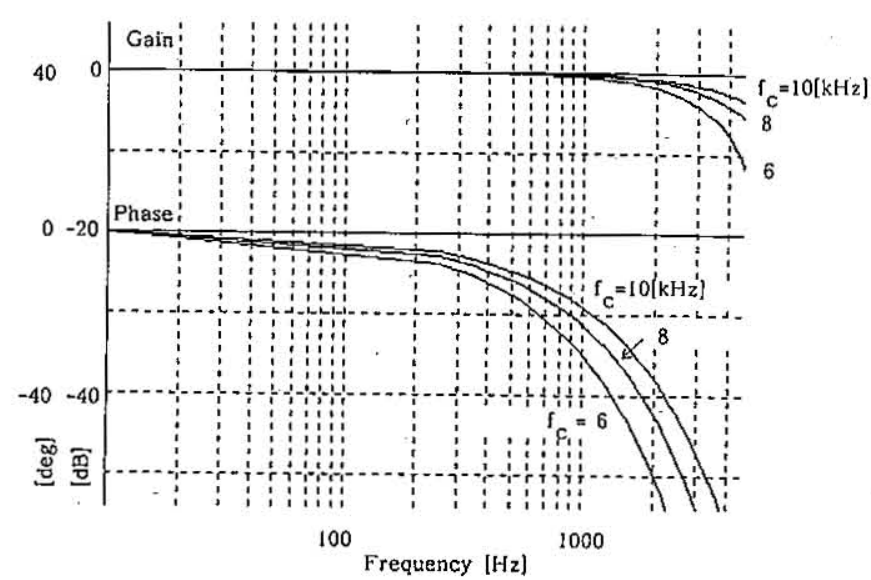

Fig. 8. Bode plots of current source converter $G_{\mathrm{CSC}}$.

\section{DC Current Control of AF}

The dc current of AF should be the minimum necessary value because too little dc current results in poor filter performance and too much dc current results in excess loss in the $\mathrm{dc}$ reactor. Therefore, the maximal value of the AF current reference in one period of the source frequency is chosen as the dc current reference in the next period, which is useful to reduce AF running loss. The control is based on a $P-I$ algorithm as

$$
G_{P I}=K_{P}\left(1+\frac{1}{T_{I} s}\right)
$$

where $K_{P}=0.4$ and $T_{I}=50 \mathrm{~ms}$. The dc current control is carried out every period of the source frequency.

\section{STABILITY INVESTIGATIONS}

It is expected that higher $G_{i}$ gains may result in better $\mathrm{AF}$ performance. However, too much gain may cause instability in the system. Here feedback control system design is based on a transfer function approach [7].

\section{A. Identification of the Transfer Function of AF}

Identification of the transfer function of AF is essential for the control system design. Responses of a current source converter (CSC) to sinusoidal current references with various frequencies were simulated under the modulation index, $M=$ $1\left(M=I^{*} / I_{d}, I^{*}\right.$ : amplitude of the reference, $I_{d}$ : dc current of $\mathrm{CSC}$ equal to $10 \mathrm{~A})$ and $f_{s}=f_{c}\left(f_{s}\right.$ : sampling frequency, $f_{c}$ : carrier frequency). The CSC output includes many harmonics but the relation of input to output at the fundamental frequency was examined. Then the transfer characteristics, $G_{\mathrm{AF}}^{*}$, shown in Fig. 8 were obtained [7]. In the figure, significant phase lag is observed in the high-frequency region because reference values are kept constant during the sampling interval. Simulation was also done under various $M$ values but it did not result in much difference in the responses. It is concluded with these simulation results that the transfer characteristic of the 


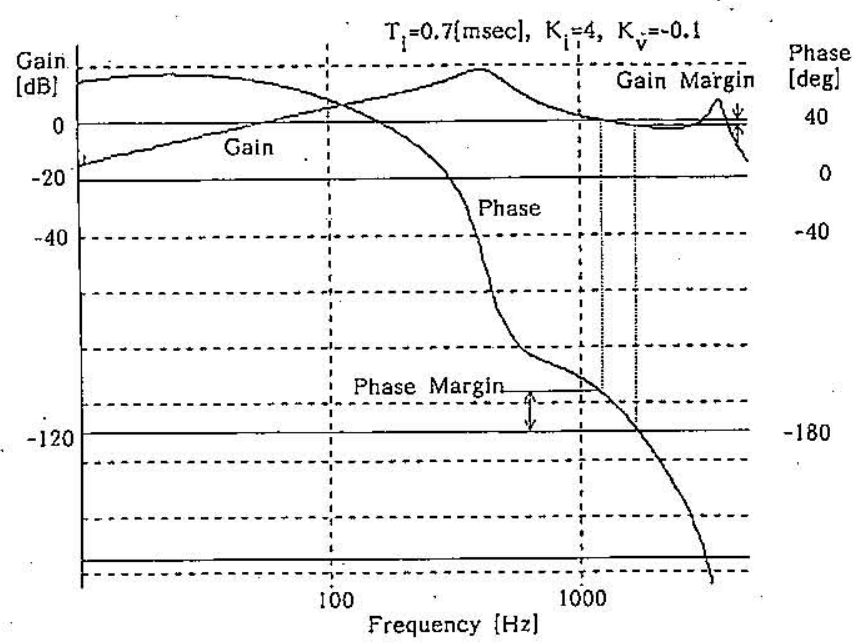

Fig. 9. Bode plots of loop transfer function $\left(G_{i}-G_{v} Z_{s}\right) G_{\mathrm{AF}} G_{z 1}$.

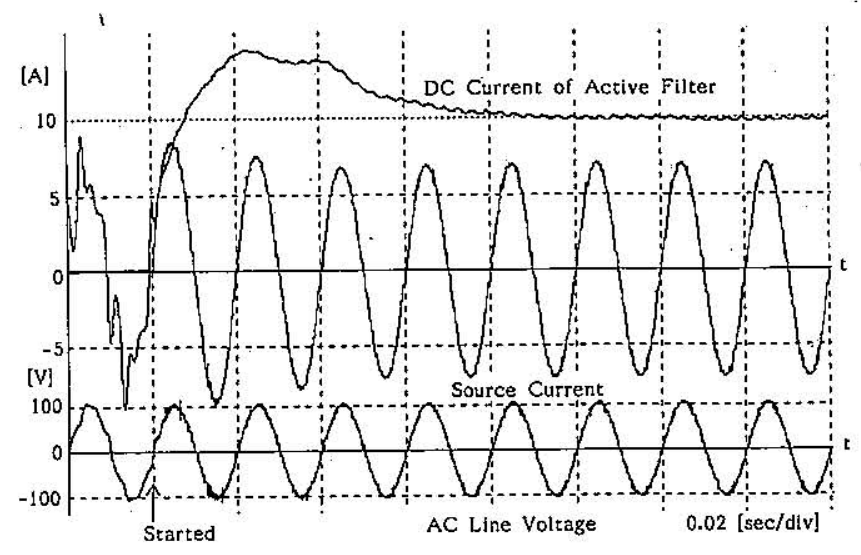

Fig. 10. Simulation results under $I_{\mathrm{Lh}}$ and $I_{\text {sh }}$ sensing.

CSC, $G_{\mathrm{CSC}}$, can be approximated as a first order lag $q$ lement in the frequency region, $f<f_{c} / 3$, and is given by

$$
G_{\mathrm{CSC}}=\frac{K}{1+T s}
$$

where $K=1.0$ and $T=1 /\left(2 f_{c}\right)$. It has been reported that the transfer function of a voltage source converter is also approximated by a first order lag element [4], but it exhibits strong nonlinearity, i.e., the delay time $T$ in (15) depends on the amplitude of the AF reference current. However, $T$ is independent of the amplitude of AF reference with the CSC unless the reference exceeds the dc current $I_{d}$.

Taking the computational time-lag $\Delta T$ and the anti-aliasing filter with its cutoff frequency $4.8 \mathrm{kHz}$ into consideration, the transfer function of CSAF, $G_{\mathrm{AF}}$, will be expressed by .

$G_{\mathrm{AF}}=\frac{G_{\mathrm{CSC}}}{1+T_{a} s} \exp (-\Delta T s)=\frac{K}{1+T s} \frac{1}{1+T_{a} s} \exp (-\Delta T s)$

where $T=f_{c} / 2=0.05 \mathrm{~ms}, T_{a}=0.03 \mathrm{~ms}$, and $\Delta T=$ $1 / f_{c}=100 \mu \mathrm{s}$.

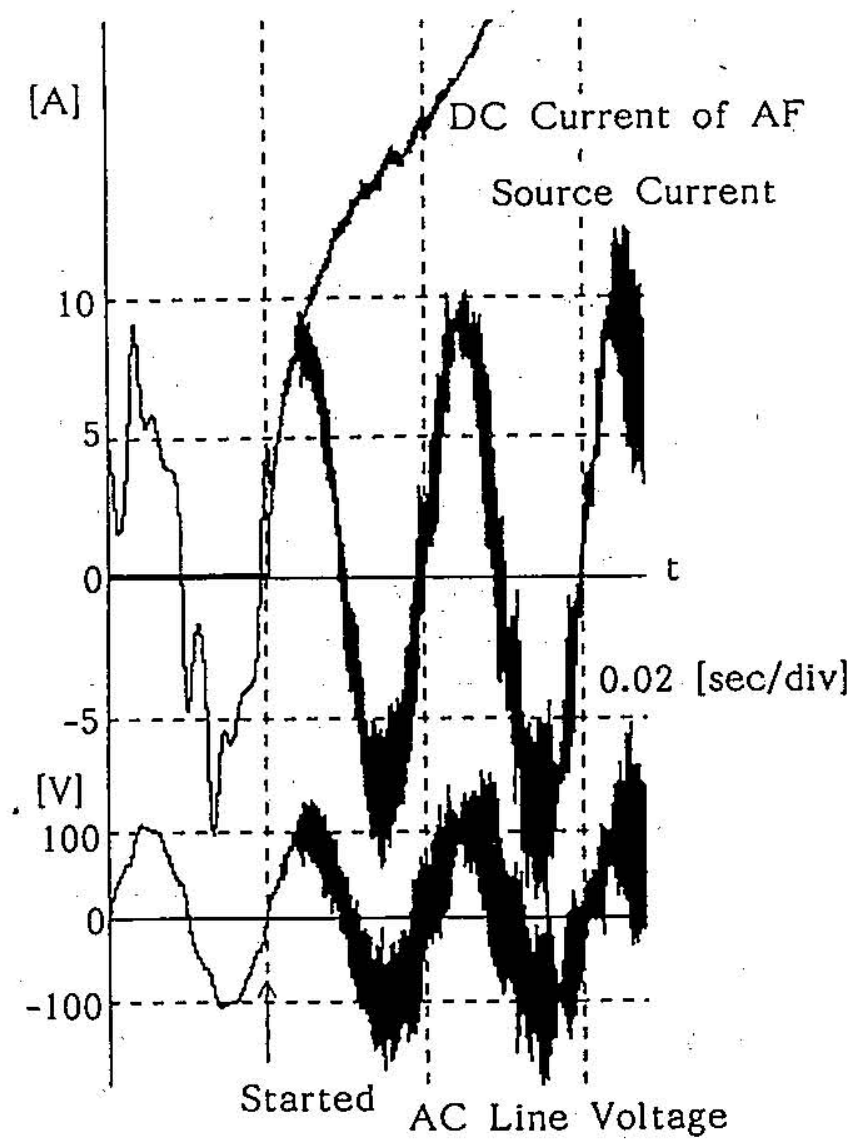

Fig. 11. Simulation results indicating instability.

\section{B. Stability Investigation and Control System Design}

Bode plots of the loop transfer function, $G_{i} G_{\mathrm{AF}} G_{z 1}$ in (8) are calculated under various $K_{i}$ and $T_{i}$, values. As a result when $K_{i}=4.0$ and $T_{i}=0.7 \mathrm{~ms}$, the phase margin of $21.0^{\circ}$ at $1141 \mathrm{~Hz}$ and the gain margin of $1.9 \mathrm{~dB}$ at $1467 \mathrm{~Hz}$ are obtained. Further increase in $K_{i}$ makes it difficult to stabilize the system.

Again simulation of the loop transfer function, $\left(G_{i}-\right.$ $\left.G_{v} Z_{s}\right) G_{\mathrm{AF}} G_{z 1}$ in (11) is done with various $K_{v}$ values. Its frequency characteristics under $K_{i}=4.0, T_{i}=0.7 \mathrm{~ms}$ and $K_{v}=-0.1$ are shown in Fig. 9. With this value, the phase margin of $25.8^{\circ}$ at $1227 \mathrm{~Hz}$ and the gain margin of $2.1 \mathrm{~dB}$ at $1678 \mathrm{~Hz}$ are obtained, which means that the line voltage feedback provides us with a more stable system.

\section{SimULATION RESULTS}

Fig. 10 shows a simulation result under $I_{\mathrm{Lh}}$ and $I_{\mathrm{sh}}$ sensing with $K_{i} \doteq 4$ and $T_{i}=0.7 \mathrm{~ms}$, and a three-phase diode rectifier. Sinusoidal source current is obtained after AF starts operation. Fig. 11 shows simulation results under the same conditions as in Fig. 10 except for $K_{i}=5.0$. Stability examination of this case reveals that the phase margin is $1.2^{\circ}$ at $1485 \mathrm{~Hz}$, and the gain margin is $0.1 \mathrm{~dB}$ at $1467 \mathrm{~Hz}$. It is seen that the source current diverges at the frequency around $1550 \mathrm{~Hz}$, which proves that the stability investigation is reasonable. 

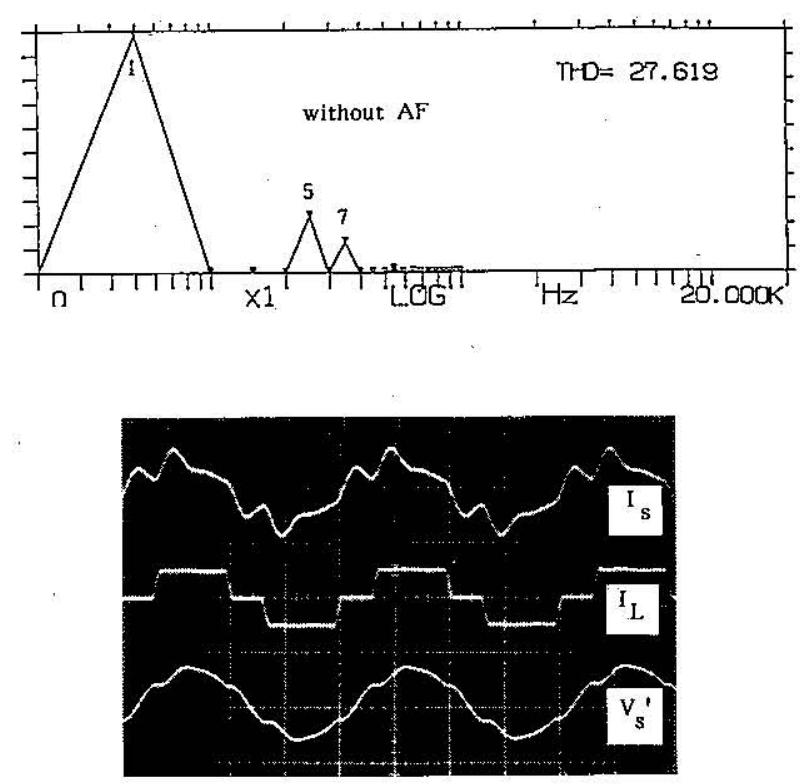

(a)
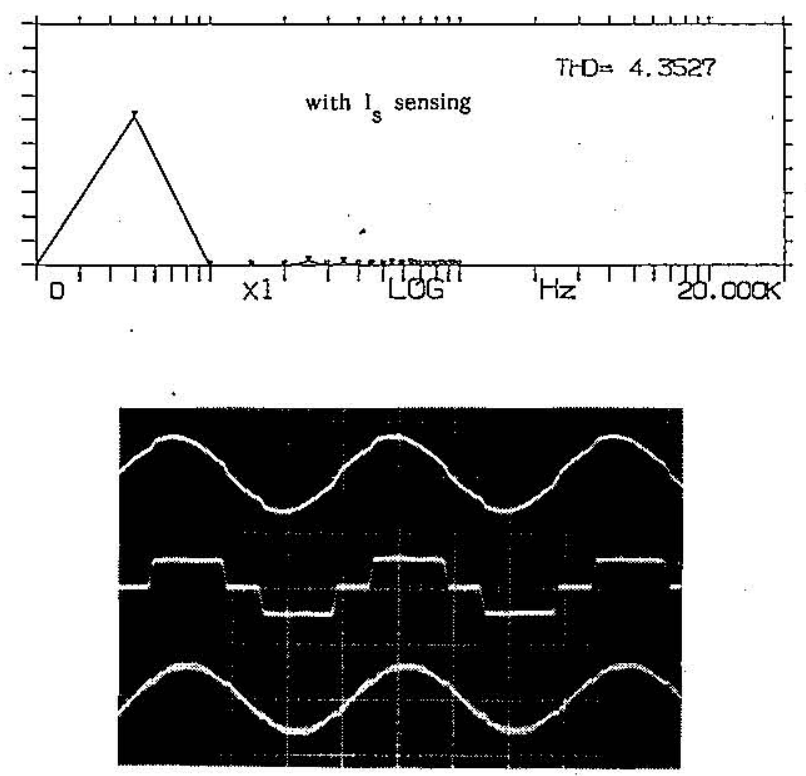

(c)
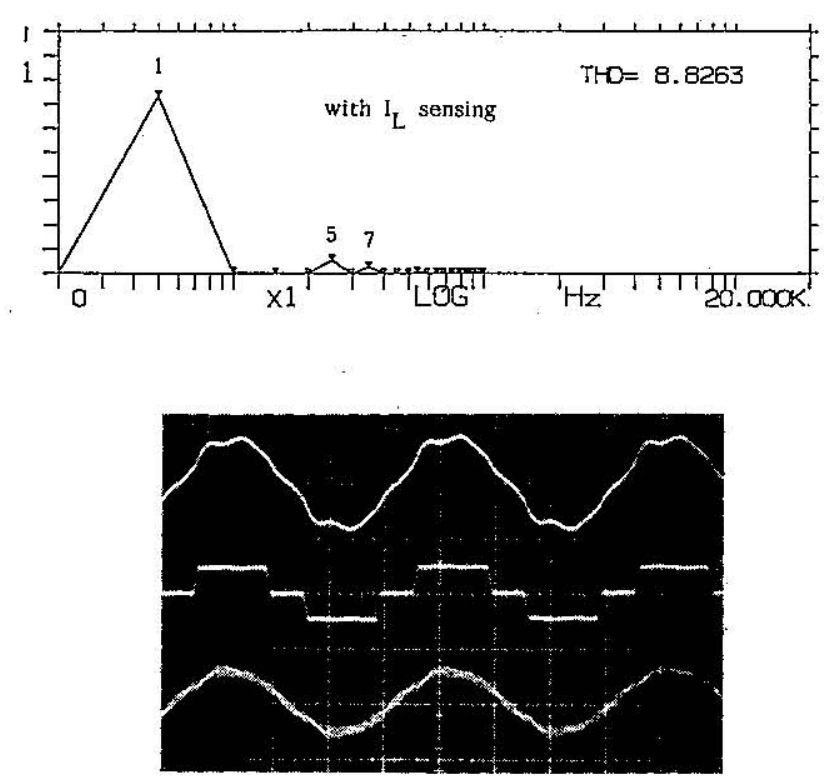

(b)
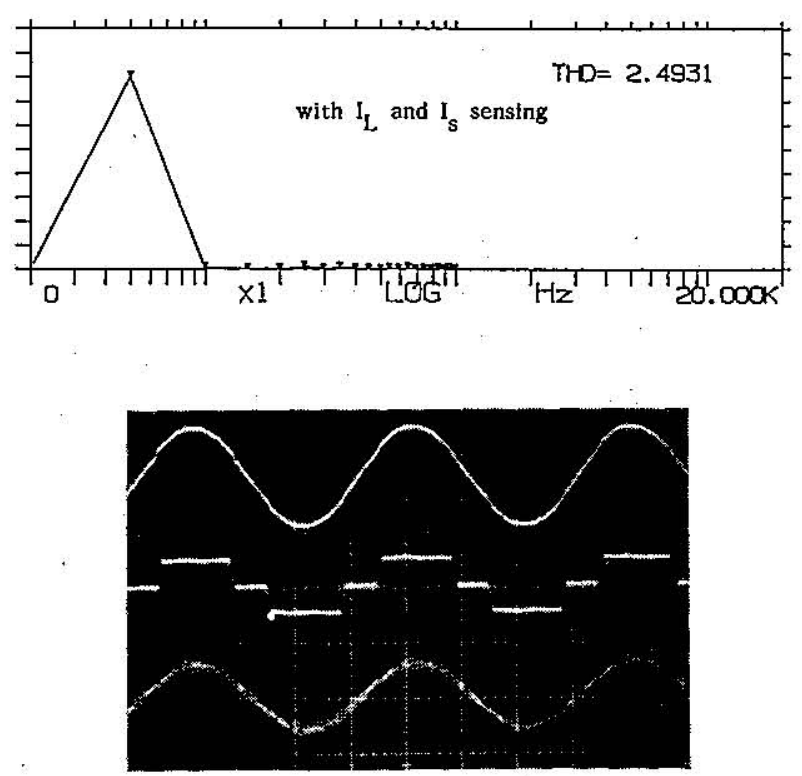

(d)

Fig. 12. Comparison of measured voltage and current waveforms in steady state under four current sensing methods. Upper: source current $I_{s}$, $10 \mathrm{~A} /$ div; middle: load current $I_{L}, 10 \mathrm{~A} / \mathrm{div}$; lower: line voltage $V_{s}^{\prime}, 177 \mathrm{~V} / \mathrm{div} ; 5 \mathrm{~ms} / \mathrm{div}$. (a) Without AF. (b) With $I_{L}$ sensing. (c) With $I_{s}$ sensing, $K_{i}=0.4$, $T_{i}=0.7 \mathrm{~ms}$. (d) With $I_{L}$ and $I_{s}$ sensing, $K_{i}=0.4, T_{i}=0.7 \mathrm{~ms}$.

Because experimental confirmation of the effects of the $V_{\text {sh }}^{\prime}$ feedback is difficult, it was done by simulation. The conditions were: the source voltage of $V_{s}=100 \mathrm{~V}$ was assumed to include 5,7 , and 11 th harmonics with each amplitude being $7 \%$ of $V_{s}$, and $I_{\mathrm{Lh}}=0$ to make clear the effects of the $V_{\mathrm{sh}}^{\prime}$ feedback alone. The THD value of the source current without feedback was $114 \%$, but it was reduced to $33.1 \%$ with the $I_{\text {sh }}$ feedback and to $26.7 \%$ with the $I_{\mathrm{sh}}$ and $V_{\mathrm{sh}}^{\prime}$ feedbacks. From these results it was confirmed that the $I_{\mathrm{sh}}$ feedback is the most effective but the $V_{\mathrm{sh}}^{\prime}$ feedback is also effective to compensate for harmonics generated by $V_{\text {sh. }}$.

\section{EXPERIMENTAL RESULTS}

A prototype 1-kVA active filter was built and experiments were done using it. Fig. 12 shows the waveforms of source current $I_{s}$, load current $I_{L}$, and line voltage $V_{s}^{\prime}$; and the spectra of $I_{s}$, where the vertical is with a linear scale and the horizontal is with a logarithmic scale. The load was a three-phase thyristor rectifier with the control angle $\alpha=0^{\circ}$. Fig. 12(a) shows the waveforms before compensation. It can be seen that the 5th and 7th harmonics are enlarged by the parallel resonance, and that the THD of $V_{s}^{\prime}$ is increased up to $8.0 \%$ while it was 
TABLE II

Comparison of Source Current Spectra Under Various Sensing Methods

\begin{tabular}{rlllll}
\hline $\begin{array}{c}\text { Order } \\
k\end{array}$ & None & $I_{L h}$ & $\begin{array}{l}\text { Sensed Variables } \\
I_{s h}\end{array}$ & $I_{L h+I_{s h}}$ & $I_{L h+I_{s h}+V_{s h}}$ \\
\hline 5 & $24.15 \%$ & $7.67 \%$ & $2.97 \%$ & $1.66 \%$ & $1.61 \%$ \\
7 & 13.24 & $\mathbf{3 . 9 9}$ & 2.51 & 1.13 & 0.65 \\
11 & 1.61 & 1.06 & 1.24 & 0.64 & 0.46 \\
13 & 0.89 & 0.51 & 1.16 & 0.80 & 0.46 \\
17 & 0.41 & 0.27 & 0.66 & 0.33 & 0.35 \\
19 & 0.35 & 0.27 & 0.54 & 0.33 & 0.16 \\
THD & 27.62 & $\mathbf{8 . 8 3}$ & 4.35 & 2.49 & 1.98 \\
\hline
\end{tabular}

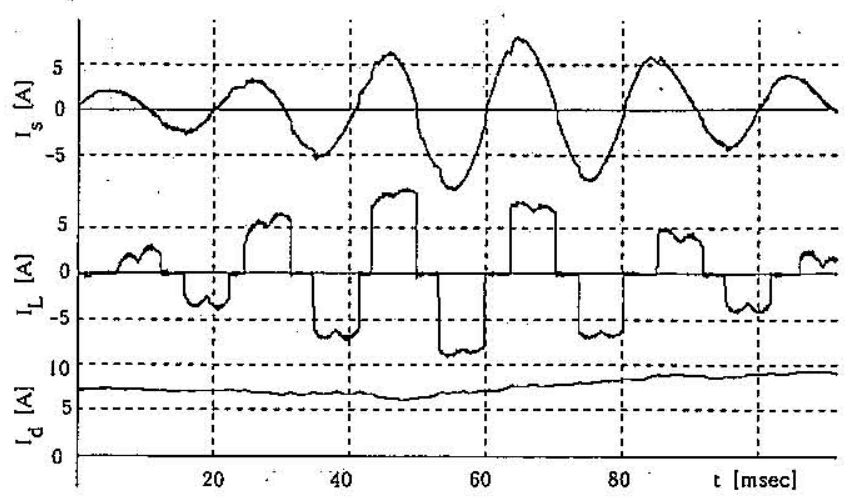

Fig. 13. Measured voltage and current waveforms.in transient state with $I_{L}$ and $I_{s}$ sensing. $K_{i}=0.4, T_{i}=0.7 \mathrm{~ms}$.

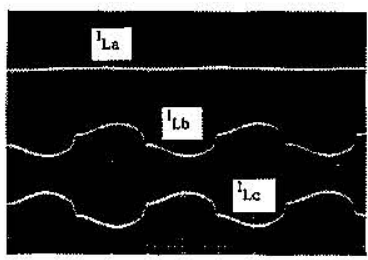

(a)

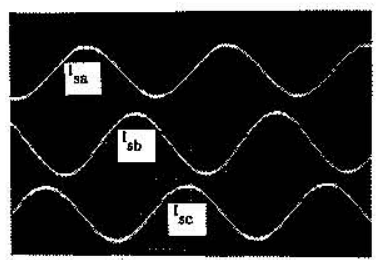

(b)
Fig. 14. Measured three-phase current waveforms for unbalanced load compensation, with a single phase diode rectifier load connected between phase "b" and "c." (a) Load currents, $10 \mathrm{~A} /$ div. (b) Source currents, $7.5 \mathrm{~A} / \mathrm{div}$, with $I_{L}, I_{s}$ and $V_{s}^{\prime}$ sensing. $K_{i}=0.4, T_{i}=0.7 \mathrm{~ms}, K_{v}=-0.1,7.5 \mathrm{~A} / \mathrm{div}$, and $5 \mathrm{~ms} / \mathrm{div}$.

$0.82 \%$ at no load. Fig. 12(b)-(d) show the waveforms and the source current spectra after the compensation with threeway sensing control. In the $I_{\mathrm{Lh}}$ feedforward of Fig. 12(b), suppression of the parallel resonance around $400 \mathrm{~Hz}$ is not great enough and influence of the computational time-lag is seen. In the $I_{\text {sh }}$ feedback of Fig. 12(c), suppression of the 5 th and 7 th harmonics is better but the other harmonics are larger than the $I_{\mathrm{Lh}}$ feedforward. In the $I_{\mathrm{Lh}}+I_{\mathrm{sh}}$ sensing of Fig. 12(d) and $I_{\mathrm{Lh}}+I_{\mathrm{sh}}+V_{\mathrm{sh}}^{\prime}$ sensing (photo is not shown in this case), excellent compensation results are observed. The source current harmonic list under various variable sensing conditions is summarized in Table II.

The compensation results when the control angle of the rectifier was changed continuously and periodically under the $I_{\mathrm{Lh}}+I_{\text {sh }}$ sensing are shown in Fig. 13. The dc current follows the variations in $I_{L}$ behind the time around $50 \mathrm{~ms}$. As the purpose of the $I_{d}$ control is to minimize running loss in the
TABLE III

COMPARISON OF CURRENT SPECTRA

\begin{tabular}{ccc}
\hline $\begin{array}{c}\text { Order } \\
k\end{array}$ & $\begin{array}{c}\text { Load } \\
\text { Current }\end{array}$ & $\begin{array}{c}\text { Source } \\
\text { Current }\end{array}$ \\
\hline 1 & $100 \%$ & $100 \%$ \\
3 & 12.8 & 1.30 \\
5 & 8.14 & 0.87 \\
7 & 5.52 & 0.24 \\
9 & 4.14 & 0.47 \\
11 & 3.11 & 0.32 \\
13 & 2.35 & 0.20 \\
15 & 1.79 & 0.24 \\
17 & 1.38 & 0.08 \\
19 & 1.07 & 0.18 \\
THD & 17.3 & 1.79 \\
\hline
\end{tabular}

steady state, the response delay of $50 \mathrm{~ms}$ is no problem. The load current is almost sinusoidal, which indicates that the proposed AF system is useful in the transient state as well.

Fig. 14 shows compensation for an unbalanced load when a single phase diode rectifier was connected between phase "b" and "c," and phase "a" was left open. Fig. 14(a) shows the load current waveforms of each phase, and (b) shows the source current ones of each phase. Balanced three-phase source currents are seen after compensation. The load and source current harmonic lists of phase " $b$ " are given in Table III.

\section{CONCLUSION}

The CSAF control method, which senses load current, source current, and line voltage, was described. The transfer characteristics of CSAF were examined and it was found that it could be approximately represented by a first order lag function. Stability investigation was then carried out and a control system design based on the transfer function approach was proposed. It was pointed out that if a microprocessor is used in the control system, the time-lag in the output caused by the computation time results in serious deterioration in the compensation performance. It was shown by experiment as well as simulation that an appropriate control system design using load current feedforward, source current feedback, and line voltage feedback can compensate for not only the harmonics generated by load harmonic current and/or source harmonic voltage but the time-lag problems as well. With the proposed control method, almost every kind of harmonics of current source nature can be compensated for as long as the system parameters remain constant.

\section{ACKNOWLEDGMENT}

The authors express their sincere thanks to S. Itoh of Hitachi Research Laboratory Co. Ltd., and M. Yamaji of Pioneer Co. Ltd., the former graduate students, for their great initial efforts toward this project. 


\section{REFERENCES}

[1] S. Itoh and S. Fukuda, "Basic characteristics of active power filter using current source converter," Conf. Rec. of IEEJ Ind. Applicat. Soc. Nat. Conv., no. 67, pp. 301-306, 1988.

[2] T. Endoh and S. Fukuda, "Compensation characteristics of combined active filter system using current source converter and high pass filter," Conf. Rec. of IEEJ Static Power Converters, SPC-90-43, 1990.

[3] T. Ise et al., "Compensation characteristics of the active filter using a current source PWM converter," Conf. Rec. of IPEC-Tokyo, pp. 791-798, 1990.

[4] W. Zhaoan et al., "Compensation characteristics and dynamics of the active filter for superconducting magnet energy storage," IEE of Japan Trans., vol. 108, no. 12, pp. 1107-1114, 1988.

[5] S. Fukuda and M. Yamaji, "Design and characteristics of active power filter using current source converter," IEEE IAS Annu. Meeting, pp. 965-970, 1990.

[6] H. Akagi et al., "Instantaneous reactive power compensation comprising switching devices without energy storage elements," IEEE Trans. Ind. Applicat., vol. 20, no. 3, pp. 625-630, 1984.

[7] T. Endoh, S. Fukuda et al., "Control and stability investigation of active filter system using a current source PWM converter," Conf. Rec. of IEEJ Ind. Applicat. Soc. Nat. Conv, no. 114, pp. 502-507, 1991.

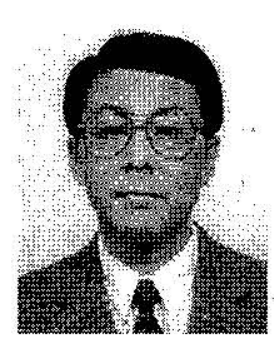

Shoji Fukuda (M'85) received the B.E.E., M.E.E., and $\mathrm{Ph} . \mathrm{D}$. degrees from Hokkaido University, Sapporo, Japan, in 1965,1967 , and 1977 , respectively.

In 1967, he joined the Faculty of Engineering, Hokkaido University, where he is an Associate Professor in the Department of Electrical Engineering. From 1981 to 1983 , he pursued research activities at the University of Saskatchewan, Canada, as a postdoctoral fellow. He has been engaged in the research of microprocessor-based PWM control of rectifiers/inverters, ac drives, and active power filters.

Dr. Fukuda is a member of the Institute of Electrical Engineers of Japan.

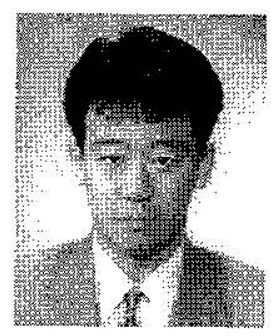

Takayoshi Endoh received the B.E.E. and M.S.E.E. degrees from Hokkaido University, Sapporo, Japan, in 1990 and 1992, respectively.

In 1992, he joined Komatsu Ltd., Research Division, Hiratsuka, Japan. He is engaged in research and development of electronics for industrial applications.

Mr. Endoh is a member of the Institute of Electrical Engineers of Japan. 